\title{
Öber die Bildung freien Stickstoffes bei der Darmgärung.
}

\author{
Von
}

\author{
Angust Krogh.
}

(Aus dem physiologischen Laboratorium der Universität Kopenhagen.)

(Der Redaktion zugegangen am 24. November 1906.)

Vor kurzem teilte Oppenheimer ${ }^{1}$ ) in der vorliegenden Zeitschrift eine Reihe von Versuchen über die Gärung des Darminhalts im Vakuum mit, durch die er zu beweisen bezweckt, daß kein freier Stickstoff bei solcher Gärung gebildet wird, es sei denn, daß sich im Darminhalt Nitrite finden. Bei der Analyse der betreffenden Gase fand er indes in allen Fällen einen größeren oder geringeren Stickstoffrest, der zwischen 0,2 und $0,74 \mathrm{ccm}$ oder zwischen ca. 2,5 und ca. 88\% des Gärungsgases schwankte, nachdem die Kohlensäure, die gewöhnlich den weit überwiegenden Teil, 69-90\%, beträgt, entfernt worden war. Diese «Spuren Stickstoff» schreibt Oppenheimer teils Fehlern der Analyse, teils dem Vorhandensein atmosphärischer Luft im Gärungsgemische $\mathrm{zu}$, indem er einerseits auf die Möglichkeit hinweist, daß mit den «großen Mengen» Sauerstoff und Wasserstoff, die zu den Explosionsanalysen angewandt werden, auch Stickstoff zugeführt werde, andererseits die Schwierigkeiten betont, den breiartigen Darminhalt vollständig auszupumpen.

Da die gefundenen Stickstoffreste indes wohl kaum mit Recht Spuren zu nennen sind, wenn die Gesamtmenge des Darmgases in keinem Falle bis $100 \mathrm{ccm}$ betrug, und da es folglich zu befürchten steht, daß die diametral entgegengesetzte Ansicht, es bilde sich normal bei der Darmgärung eine geringe Menge freien Stickstoffes, sich diese Reste zunutze machen könnte, wird es nicht überflüssig sein, Oppenheimers Resultat durch andere Versuche zu stützen.

1) Oppenheimer, Zur Kenntnis der Darmgärung. Diese Zeitschrift, XLVII, S. 240. 
Vor etwa einem Jahre unternahm ich anläßlich einer umfassenderen Untersuchung über die Bildung freien Stickstoffes im Körper ${ }^{1}$ ) ein paar ähnliche Bestimmungen des durch Gärung des Darminhalts gebildeten Gases.

Das Verfahren war folgendes: Etwa $80 \mathrm{~g}$ des Inhalts des Blinddarms eines Kaninchens wurden mit etwas Wasser gemischt und durch dünne Leinwand durchgepreßt. Das Filtrat teilte ich in zwei Portionen, die direkt in die Rezipienten der Quecksilberluftpumpen übergeführt wurden. Ich evakuierte und steigerte die Temperatur bis auf ca. 40 $0^{\circ}$ Am folgenden Tage evakuierte ich wieder und ließ darauf das Gemisch vier Tage lang bei $35-40^{\circ}$ ungestört gären. Die gebildeten Gase wurden ausgepumpt und über Quecksilber angesammelt. In den beiden betreffenden Gefäßen wurden ein paar Tropfen frisch ausgekochten $75 \%$ igen Kalis zugesetzt, wodurch die Kohlensäure absorbiert wurde. Ihre Menge wurde in beiden Rezipienten auf ca. 90\% der gesamten Gasmasse geschätzt. Die ca. 5, bezw. ca. $6 \mathrm{ccm}$ betragenden Gasreste wurden in Haldanes Analysierapparate ${ }^{2}$ ) analysiert, indem sie mit einer genau abgemessenen Menge reinen Stickstoffs gemischt wurden. Erst wurden sie auf Sauerstoff untersucht durch Absorption mit pyrogallussaurem Kali. ${ }^{3}$ ) In beiden Proben fand sich eine geringe

1) Krogh, Experimentelle Untersuchungen über die Ausatmung freien Stickstoffes aus dem Körper. Sitzungsber. der K. Akad. d. Wiss. Wien. M.-n. Klasse, Bd. CXV, Abt. III, 1906. Dieselbe Abhandlung in englischer Sprache. Skand. Arch. f. Physiol., Bd. XVIII, S. 378.

2) Haldane, Some improved methods of gas-analysis. Journ. of Physiol., 1898, Vol. XXII, p. 465-480.

$\left.{ }^{3}\right)$ Im Widerspruch mit Oppenheimer (S. 244) muß ich entschieden behaupten, daß pyrogallussaures Kali, jedenfalls wenn es nach Haldanes Vorschriften zubereitet wird (100 g Kalihydrat werden in $50 \mathrm{ccm}$ Wasser gelöst, und man setzt $10 \mathrm{~g}$ Pyrogallussäure zu), Sauerstoff schnell und durchaus vollkommen absorbiert. Dagegen kann es geschehen, daß sich bei der Absorption Spuren von Kohlenoxyd bilden, wenn nämlich die analysierte Gasmischung sehr reich an Sauerstoff ist. Man muß deshalb bei Analysen Sorge tragen, daß keine Gasmischungen mit dem pyrogallussauren Kali in Berührung kommen, dessen Sauerstoffprozent mehr als 30-40 beträgt, oder auch muß man, wenn dies sich nicht vermeiden läßt, das gebildete Kohlenoxyd verbrennen, wenn der größte Teil des Sauerstoffs absorbiert worden ist. 
Menge Sauerstoff, nämlich 0,010, bezw. 0,017 ccm. Darauf wurde eine passende Menge absolut reinen Sauerstoffes (auf elektrolytischem W'ege aus Wasser dargestellt) zugesetzt und das Gemisch mittels eines glühenden Platindrahtes in der hierzu eingerichteten Verbrennungspipette langsam verbrannt. Nachdem die erzeugte Kohlensäure absorbiert und ebenfalls der Sauerstoffüberschuß entfernt worden war, ergab es sich, daß die ursprüngliche Stickstoffmenge im Analysierapparate um 0,032, bezw. 0,050 ccm zugenommen hatte.

Aus den Analysen läßt sich folgende Zusammensetzung der ursprünglichen Gärungsgase berechnen:

\begin{tabular}{ll|c|c}
\hline & & Pumpe A & Pumpe B \\
\hline Menge . . . . . . . . . . . . . & $60 \mathrm{ccm}$ & $50 \mathrm{ccm}$ \\
Kohlensäure . . . . . . . . . . . & ca. $90 \%$ & ca. $90 \%$ \\
Brennbare Gase.......... & $9,91 \%$ & $9,88 \%$ \\
Sauerstoff . . . . . . . . . . . . & $0,03 \%$ & $0,02 \%$ \\
Stickstoff . . . . . . . . . . . . & $0,06 \%$ & $0,10 \%$
\end{tabular}

In Prozenten der kohlensäurefreien Reste beträgt der Stickstoff mithin 0,6 , bezw. 1,0\%.

Diese Stickstoffmengen, die um vielmal geringer sind als die von Oppenheimer gefundenen, rühren gewiß nicht von Fehlern der Analysen her, indem solche bei der benutzten Methode absolut nicht mehr als $0,01 \mathrm{ccm}$ betragen können, was ca. 0,2\% der analysierten Mengen entspricht, und wahrscheinlich noch bedeutend geringer sind.

Der Umstand, daß außer dem Stickstoff zugleich auch Sauerstoff gefunden wurde, und daß das gegenseitige Mengenverhältnis der beiden Gase, wenn man berücksichtigt, daß die absoluten Mengen 0,05 ccm nicht übersteigen, so ziemlich der Zusammensetzung der Atmosphäre entspricht, redet stark dafür, daß der Stickstoff sowohl als der Sauerstoff von einer Verunreinigung mit atmosphärischer Luft herrührt, da absolut nichts darauf hindeutet, daß sich freier Sauerstoff bei der Darmgärung entwickeln könnte. 
Es gibt indes keine Möglichkeit, daß nachweisbare Gasmengen während der beiden ersten Auspumpungen sollten in den Gärungsgemischen zurückgehalten worden sein, indem die Gärungsgase, die sich fortwährend im Darminhalte entwickeln, diesen sehr effektiv von allen fremden Gasen "auswaschen» werden. Überdies würde Sauerstoff, der auf diese Weise zurückgehalten worden wäre, ganz sicher während der fortgesetzten Gärungsvorgänge verbraucht werden.

Die wirkliche Erklärung des Vorhandenseins von Sauerstoff und Stickstoff in den kleinen Mengen, in welchen ich diese Gase fand, ist das Eindringen atmosphärischer Luft durch Undichtheiten der Pumpen. Quecksilberpumpen, die absolut luftdicht wären, kennt man wahrscheinlich nicht, ich wenigstens habe nie eine solche angetroffen. Hat man die Luft bis auf die letzte Spur ausgepumpt, so kann man gewöhnlich am nächsten Tage oder jedenfalls nach Verlauf einiger Tage ein Luftbläschen von meßbarer Größe gewahren. Bei den hier referierten Versuchen drangen im Laufe von 4 Tagen 0,05 , bezw. $0,06 \mathrm{ccm}$ Luft ein, was von einer so guten Dichtigkeit zeugt, wie sie sich meiner Erfahrung nach nur irgend erreichen läßt.

Es läßt sich also mit Sicherheit behaupten, daß in diesen Versuchen kein freier Stickstoff bei der Darmgärung erzeugt wurde. 